\title{
Desenvolvendo atividades colaborativas na escola
}

Caroline Lengert Guedes

Mestre em Mídia e Conhecimento pela Universidade Federal de Santa Catarina, formação em Pedagogia pela UDESC. Professora do Curso Normal Superior do Instituto Superior de Educação de Santa Catarina - ISESC/IESVILLE, Joinville - SC. E-mail: clguedes@pop.com.br

Hugo Rosenthal

Mestre em Mídia e Conhecimento pela Universidade Federal de Santa Catarina. Professor de Multimeios e Educação a Distância na Univali - SC. Sócio-diretor da Complex Informática.

E-mail: hugo@complex.com.br

A chegada das tecnologias educacionais tem influenciado significativamente o cotidiano escolar. Com freqüência esses recursos são utilizados como meros apêndices em sala de aula, apenas com o intuito de ilustrar o discurso do professor. O desafio é buscar novas metodologias de utilização de tais aparatos tecnológicos no universo escolar, no sentido de torná-los significativos no processo de ensino-aprendizado.

Modificar a prática existente demanda contemplar atividades que ultrapassem as paredes das salas de aula, dos laboratórios, que favoreçam um aprendizado significativo, desafiador, problematizador, a ponto de mobilizar o aluno a buscar soluções possíveis para serem discutidas por todo o grupo. Muitos teóricos contemporâneos são unânimes em afirmar que atividades colaborativas auxiliam no processo de ensino-aprendizado, isso porque não se consegue alunos críticos, dinâmicos, participativos, apenas em atividades de ler, escutar, decorar e repetir. A distinção entre colaboração e cooperação é tema controverso entre os autores da área. Neste trabalho utiliza-se o termo colaboração no sentido amplo de pessoas desempenhando conjuntamente uma atividade com um objetivo comum.

A informática, em geral, e a internet, em particular, oferecem um excelente ambiente para o trabalho colaborativo, possibilitando integrar indivíduos não apenas localmente, mas também a distância. Outro aspecto muito relevante é que todo o universo da internet e da multimídia tendem a aumentar o grau de motivação dos alunos.

Este artigo apresenta uma atividade colaborativa, denominada Jogos Colaborativos, desenvolvida pela empresa Complex Informática Ltda., sediada em Florianópolis, em parceria com cinco escolas da Província Marista de Santa 
1. PIAGET, Jean. Biologia e conhecimento: ensaio sobre as relações entre as regulações orgânicas e os processos cognoscitivos. Petrópolis: Vozes, 1973.

2. VYGOTSKY, Lev S. A formação social da mente. São Paulo: Martins Fontes, 1984

3. PAPERT, Seymour. A máquina das crianças: $O$ futuro do pensamento na era da informática. Porto Alegre: Artmed, 1994.

4. LÉVY, Pierre. Cibercultura. São Paulo: Ed. 34, 1999.

5. Id. As tecnologias da inteligência: o futuro do pensamento na era da informática. Rio de Janeiro: Ed. 34, 1993.
Catarina, rede que inclui o Colégio Paranaense de Curitiba - PR. Através de atividades que exigiram encontros virtuais via internet, buscou-se integrar os alunos das $8^{\text {as }}$ Séries dessas escolas, que se encontravam em estados e cidades diferentes para que, de maneira colaborativa, resolvessem as questões propostas acerca do tema Escolha a Vida.

\section{OBJETIVOS DA ATIVIDADE}

A atividade dos Jogos Colaborativos teve por objetivo ampliar a utilização da tecnologia nos trabalhos que já vêm sendo desenvolvidos nas escolas da Província Marista de Santa Catarina. Empregando a tecnologia, buscou-se propiciar uma atividade colaborativa que permitisse aos alunos a construção dos conhecimentos a partir de informações procedentes de diferentes saberes disciplinares. Além disso, também foi objetivo desta atividade favorecer o contato dos alunos com a internet e proporcionar, além das trocas de conhecimento, um intercâmbio afetivo e social.

\section{FUNDAMENTAÇÃO DO TRABALHO COLABORATIVO}

Teorias presentes no cotidiano educacional ajudam a explicar a importância de atividades colaborativas entre alunos. Na teoria piagetiana, não há uma preocupação em discutir profundamente a questão das interações sociais. Porém, diz Piaget que os indivíduos precisam construir conhecimentos em resposta a uma exigência social. Essa construção acontece nas relações de cooperação, em que há troca de informações, de idéias e argumentação. Vivenciando a cooperação, as verdades são discutidas, pois é preciso provas para convencer o outro sobre a veracidade de uma determinada afirmação ${ }^{1}$.

Segundo Vygotsky, o funcionamento psicológico fundamenta-se nas relações sociais entre o indivíduo e o mundo exterior, que se desenvolvem num processo histórico. É na interação com os outros que a criança aprende, despertando dessa forma processos internos de desenvolvimento. A relação com o outro é essencial para o processo de construção do ser psicológico individual, pois o desenvolvimento individual se dá em um ambiente social ${ }^{2}$. Questões sobre a participação dos alunos no processo de aprendizado são discutidas também por Papert. Segundo este autor, as melhores aprendizagens de um indivíduo acontecem nos momentos em que ele participa ativamente do processo, experimentando situações desafiadoras ${ }^{3}$.

Segundo Lévy ${ }^{4}$, as atividades colaborativas são uma perspectiva promissora para a evolução da inteligência coletiva em educação. Ele argumenta que quanto mais uma pessoa se envolve com determinada informação, mais fácil será para ela lembrar dessa informação em uma situação posterior ${ }^{5}$. Sendo assim, cabe aos educadores propor atividades diversificadas aos alunos, principalmente quando essas atividades permitem maior interação social entre eles, o desenvolvimento de um espírito de colaboração e de autonomia e um melhor aprendizado. 


\section{DESCRIÇÃO DA ATIVIDADE DESENVOLVIDA}

Os Jogos Colaborativos duraram dois dias e foram centralizados no site $<$ http://www.everestonline.com.br/jogos $>$, no qual os alunos puderam acessar todas as informações antes, durante e depois de concluída a atividade.

Para a realização das tarefas, os alunos foram divididos em equipes mistas, sendo que, em cada equipe, havia estudantes das cinco escolas participantes. A decisão de se formarem equipes mistas veio ao encontro de um dos objetivos centrais da atividade, que era proporcionar maior relacionamento entre os alunos das diferentes cidades. No primeiro dia dos jogos, logo pela manhã, divulgaramse no site as atividades que deveriam ser desenvolvidas ao longo dos dois dias. Cada atividade contava com quatorze questões em que os alunos precisaram interagir com colegas das outras cidades para tentar resolver uma charada que identificava a cidade onde a questão deveria ser resolvida, e depois, localmente, os alunos dessa cidade tinham de resolver a atividade, conforme exemplo:

“[...] toda faceira e bonita. Na riqueza e na opulência [...]." Esta é uma parte da letra do hino desta cidade. Atualmente, a reciclagem do lixo é um assunto que vem sendo bastante discutido, pois para que as cidades ofereçam qualidade de vida aos seus habitantes, é preciso que elas dêem um destino adequado para o lixo produzido diariamente. Identifique nesta cidade qual é o órgão responsável pela reciclagem do lixo e responda: que órgão é este, qual é a quantidade de lixo reciclada por mês e qual é a porcentagem do lixo reciclado em relação ao lixo total recolhido.

Duas questões eram coletivas, devendo ser resolvidas por todos os membros da equipe, visto que exigia dados de todas as cidades, conforme segue:

O desemprego é um problema preocupante, que se agravou bastante nos últimos anos, não só no Brasil, mas em todo o mundo. Sabe-se que as cidades envolvidas neste jogo apresentam um número satisfatório de indústrias, que geram empregos. Pesquise nestas cidades o índice de desemprego e o número de indústrias existentes. Depois, faça uma comparação, relacionando o número de indústrias em cada cidade com o índice de desemprego que elas apresentam. Apresente estes dados numa tabela e responda: em qual cidade há mais indústrias? Em qual delas o índice de desemprego é maior?

Como meio de comunicação entre os alunos, utilizaram-se chats exclusivos para cada equipe, com acesso através de senha, permitindo encontros on-line em tempo real, e também uma lista de discussão mediante a qual puderam trocar informações. Concluídas as tarefas, cada equipe ordenou as respostas finais e as enviou para a organização, que realizou as correções e, pelo site, divulgou a equipe vencedora.

\section{AVALIAÇÃO}

Buscando aprimorar e ampliar atividades dessa natureza, foi elaborado um questionário de avaliação dos Jogos Colaborativos, respondido pelos alunos, em que eles emitiram opiniões a respeito dessa primeira experiência colaborativa 
e de onde se podem tirar valiosas informações. Uma das questões pedia para os alunos avaliarem a atividade como um todo. No gráfico 1 é possível ver a distribuição percentual das respostas dadas.

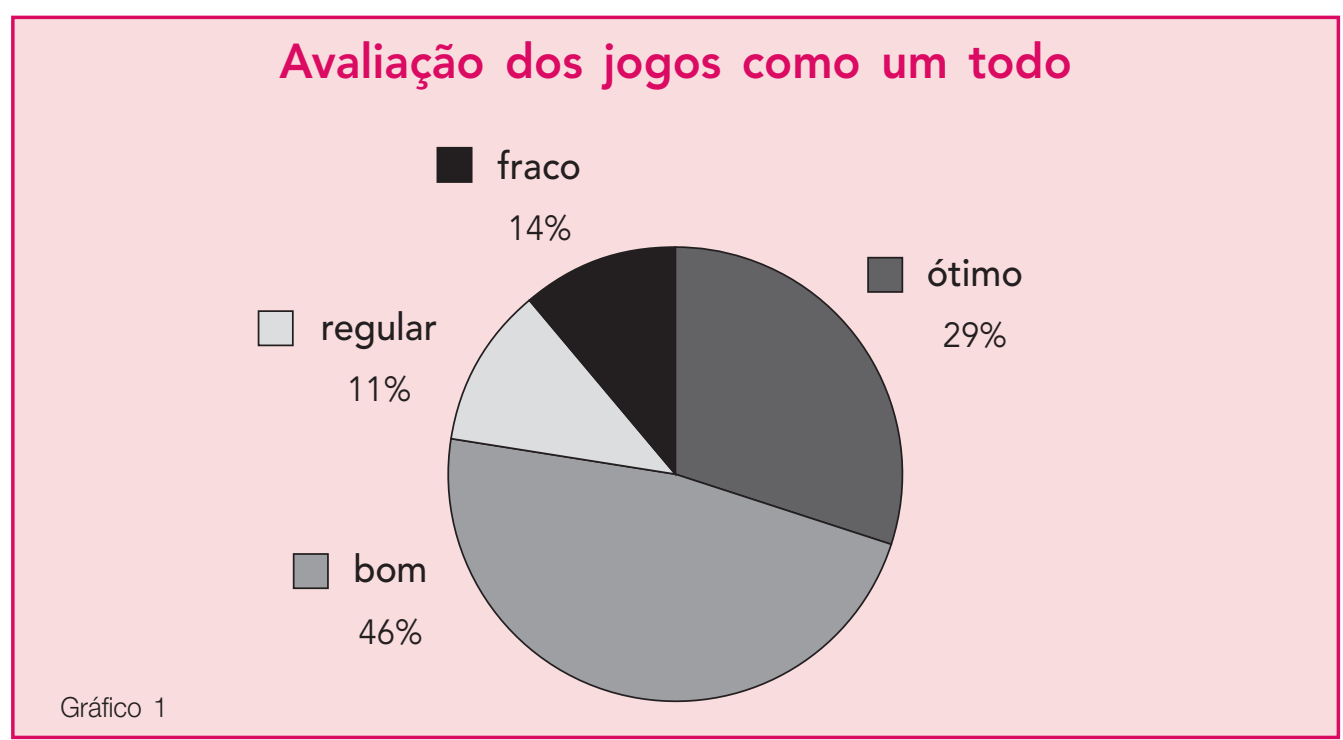

Do total, $75 \%$ dos alunos classificaram a atividade como ótima ou boa. Considerando-se ter sido a primeira vez que esses alunos realizaram uma atividade colaborativa através da internet, o resultado é bastante satisfatório. Ao analisar os próximos itens, encontram-se algumas razões que levaram $25 \%$ dos alunos a não considerarem satisfatória a atividade. Tais itens ajudam a diagnosticar onde, na visão dos alunos, ocorreram problemas.

$\mathrm{Na}$ questão que solicitava aos alunos uma avaliação do chat, o índice de respostas ótimo e bom sofre uma queda quando comparado à qualificação geral dos jogos (gráfico 2).

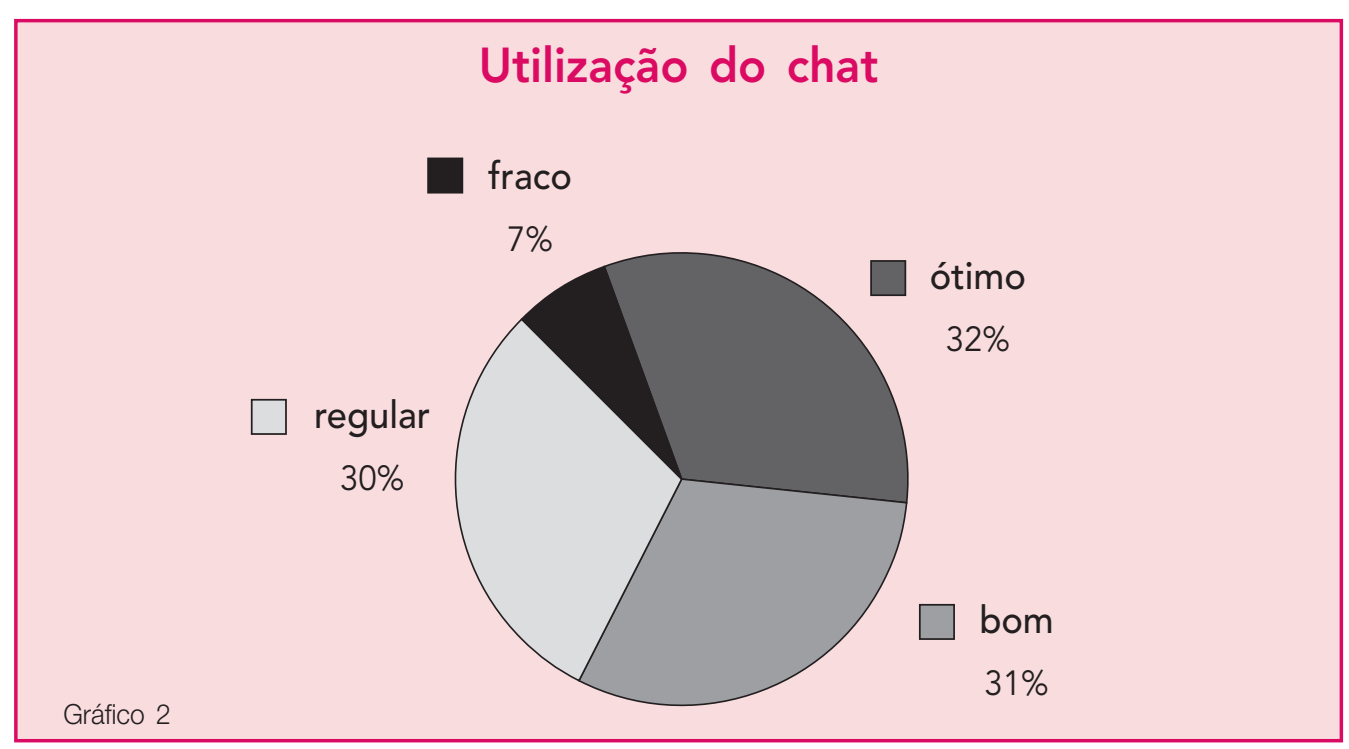


O chat foi o principal veículo de comunicação entre os alunos. A verificação dos chats das 10 equipes participantes mostrou alguns aspectos que podem ser melhorados e, possivelmente, explicam o índice de 37\% de alunos que classificaram este item como regular ou fraco. Diversas equipes não conseguiram se organizar no chat. Houve momentos em que os alunos enviavam muitas mensagens simultâneas, acarretando perda de tempo até que conseguissem, primeiro, entender as questões e, depois, dividir as tarefas entre os membros das diversas cidades. Observou-se uma relação direta entre as equipes que obtiveram os melhores resultados e aquelas que foram capazes de se organizar no chat. Outro aspecto foi a falta de uma mediação mais efetiva por parte da equipe da Complex e dos professores das escolas, principalmente para as equipes que encontraram dificuldades de organização. Certamente, nas próximas atividades será dada maior ênfase a esse aspecto.

Outro item que gerou críticas dos participantes foi o tempo previsto para a resolução das atividades, conforme mostra o gráfico 3.

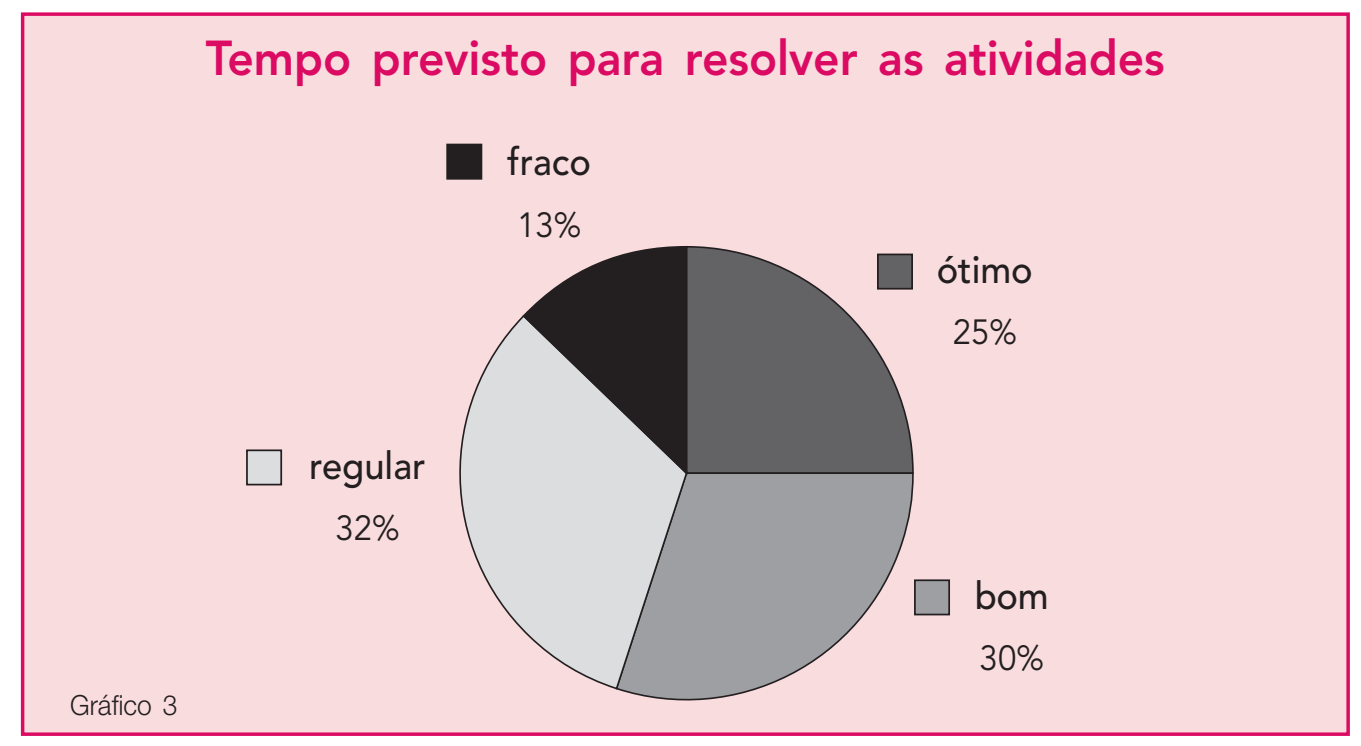

Quase 50\% dos alunos não consideraram o tempo satisfatório. Um dos fatores que pode ter prejudicado alguns deles com relação ao tempo foi a não-inserção dos jogos no calendário escolar de algumas escolas, ocasionando conflito com outras atividades que aconteceram no mesmo horário. Isso fez com que os alunos precisassem desviar sua atenção para a realização de outros trabalhos, não podendo se dedicar em período integral à resolução das questões dos jogos.

Apesar dos problemas ocorridos, a quase totalidade dos alunos deseja continuar atividades colaborativas, o que é percebido no gráfico 4 . 


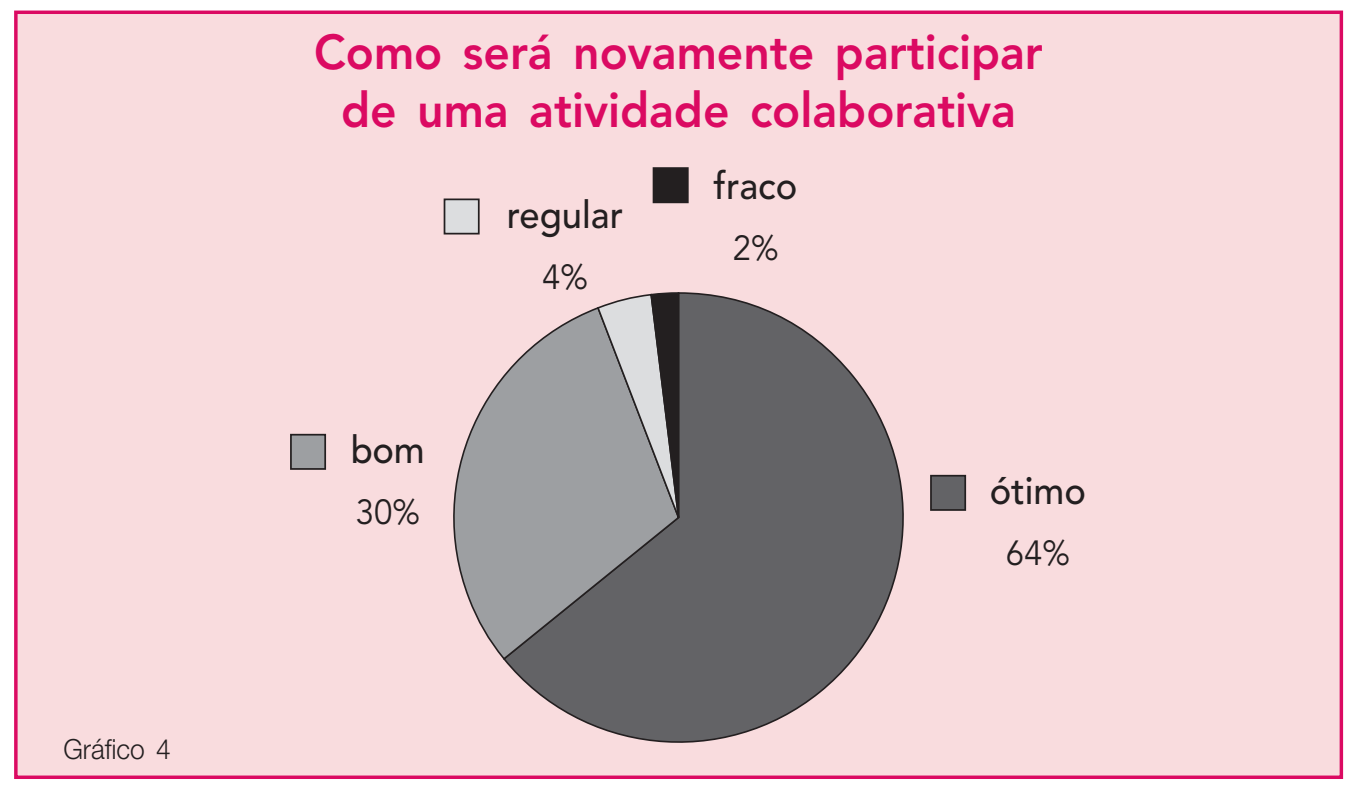

Pode-se observar que o trabalho em grupo propiciou interação e novas amizades aos alunos participantes, mas exigiu paciência e organização, sendo estes os fatores determinantes no rendimento e no desempenho final das equipes. Aqueles que, desde o início, conseguiram se organizar no chat e na resolução das atividades, chegaram ao final com maior número de questões respondidas, conquistando melhor colocação. A necessidade de um líder, ou de alguém responsável pela organização da equipe, foi sentida e apontada pelos alunos na avaliação. Para cada equipe, havia sido designado o grupo de uma das cidades para ser o responsável pela entrega final das atividades. O envolvimento desse grupo líder dentro de cada equipe também foi um dos fatores determinantes no resultado alcançado. Equipes em que os líderes não demonstraram interesse e se mantiveram afastados de suas funções apresentaram baixo rendimento, ao contrário das equipes nas quais os líderes se empenharam, preocuparam-se do início ao fim com o andamento dos colegas, mandando e-mail, conversando no chat, enfim, incentivando a todos da equipe em busca de um resultado satisfatório.

Os alunos acharam a atividade realizada muito produtiva para ampliar os conhecimentos e solicitaram que ela aconteça todos os anos, pois dessa forma podem conhecer mais sobre várias cidades e sobre assuntos da atualidade.

Até mesmo os professores envolvidos na organização e acompanhamento dos alunos responderam a um questionário de avaliação. Para eles, a atividade foi muito interessante e valeu a pena, pois motivou os alunos a trabalharem com colegas de cidades distantes, promoveu o entrosamento entre os alunos das várias escolas participantes, além de incentivar a busca de informações e a utilização do computador como ferramenta para as pesquisas.

O ponto fraco observado foi a organização e o entrosamento dos alunos dentro das equipes. A hipótese levantada é de que eles não têm experiên- 
cia em trabalhos colaborativos. Apesar de várias teorias contemporâneas de aprendizado sugerirem atividades pedagógicas em que os alunos se envolvam e participem ativamente, observa-se que nas escolas, de modo geral, não se sabe como trabalhar de maneira cooperativa. Insiste-se em um ensino fragmentado e individualizado, deixando-se de explorar atividades coletivas, que exigem dos alunos discussão e posicionamento ante os assuntos tratados.

Demonstrações favoráveis à realização de jogos colaborativos entre escolas foram pontuadas pelos professores na ficha de avaliação e ainda através de e-mail. Receberam-se várias manifestações positivas, como as que seguem:

Parabéns pela iniciativa dos jogos. Realmente valeu a pena. O empenho foi geral, tanto dos alunos como da própria equipe do Laboratório. Foi uma experiência muito gratificante. Espero que tenhamos mais atividades desse tipo.

Parabéns! A novidade, a diversão e a brincadeira como ferramenta de aprendizagem faz a diferença na educação. Esperamos por novas propostas. Até lá!

Devemos mesmo incentivar o espírito de equipe e colaboração, a entreajuda, e promover mais eventos dessa qualidade.

\section{CONSIDERAÇÕES FINAIS}

Com o advento da internet, as possibilidades para o desenvolvimento de trabalhos colaborativos já estão ao alcance da escola. Com a ajuda das redes de informação, hoje é possível para um grupo fisicamente distante desenvolver tarefas que visam alcançar um objetivo comum, favorecendo a interação social entre alunos e a troca de conhecimentos entre eles.

Com a realização dessa atividade, observaram-se inúmeros aspectos positivos, que enriqueceram e contribuíram para o processo ensino-aprendizado. Detectaram-se também alguns pontos que precisam ser revistos e aprimorados, para que atividades de colaboração entre alunos ocorram com freqüência cada vez maior no ambiente escolar.

Como aspectos positivos, tem-se: a integração com alunos de outras escolas; o trabalho em equipe; os conhecimentos adquiridos no manuseio do computador e da internet; o aprendizado sobre a história das cidades, bem como dos estados; a conquista de novas amizades; a experiência do trabalho em grupo.

Como pontos a serem melhorados, pode-se citar: mais tempo para realização das atividades; melhor organização entre os alunos, buscando-se maior colaboração; motivação para uma participação mais efetiva, visto ser um trabalho coletivo; maior esclarecimento sobre o funcionamento dos jogos, evitando-se contratempos durante os dias da atividade.

Ao trazer um pouco da realidade vivenciada fora da escola para a sala de aula, por meio de propostas como a dos Jogos Colaborativos, em que o aluno não é apenas receptor de informações, mas participante ativo do processo de aprendizado, espera-se estar contribuindo para uma educação transformadora, preocupada com a formação dos estudantes. 
Resumo: A internet e os computadores têm sido apontados como recursos de grande potencial no sentido de incrementar atividades colaborativas entre alunos situados em locais distantes. Aproveitando-se destes recursos, realizou-se, no primeiro semestre de 2001, uma atividade denominada Jogos Colaborativos, envolvendo alunos das 8as Séries de cinco escolas da Província Marista de Santa Catarina - SC. Durante dois dias, os alunos desenvolveram uma atividade colaborativa na qual o principal meio de comunicação foi a internet. $O$ presente trabalho visa descrever, analisar e avaliar essa atividade, na perspectiva de divulgá-la e ampliá-la no ambiente escolar.

Palavras-chave: colaboração, internet na educação, chat, informática, jogos.
Abstract: Internet and computers have been pointed out as resources of great potential to develop cooperative activities among students located at distant cities. Using those resources, in the first semester of 2001, an activity called Jogos Colaborativos (Collaborative Games) was held with the participation of 8th grade students of five schools of the Província Marista of Santa Catarina State. Students have developed, for two days, a collaborative activity whose the main media was internet. This article describes, analyzes and evaluates that activity, for disclosing and enlarging it in the school environment.

Keywords: collaboration, internet use in education, chat, informatics, games. 